\title{
LA DIVISA DE LAS GRANADAS DEL REY ENRIQUE IV DE CASTILLA Y SU ESTELA POSTERIOR ${ }^{1}$
}

\author{
KING HENRY IV OF CASTILE'S IMPRESA OF THE POMEGRANATES AND \\ ITS SUBSEQUENT IMPACT
}

Sagrario López Poza
Universidade da Coruña

ABSTRACT: This study analyzes the meaning of the impresa or device of the pomegranates, with the motto "Agro dulce», utilized by Henry IV (1425-1474), of the House of Trastámara, King of Castile from 1454 until his death. By means of a review of vestiges that remain of the device, especially in architectonic elements, I postulate that the pomegranate may have been used as the family impresa of the House of Trastámara and their descendants. This, it seems, can be deduced from the pictura of the device in several personal imprese of relatives who lived in the sixteenth century.

KEYWORDS: pomegranate, devices, royal clemency, Henry IV, Catholic Monarchs, Catherine of Aragon, Charles V, Philip II of Spain.

RESUMEN: Se analiza el significado de la empresa o divisa de las granadas, con el mote "Agro dulce» empleada por Enrique IV (1425 -1474), de la casa de Trastámara, rey de Castilla desde 1454 hasta su muerte. Se da noticia de vestigios que se encuentran de la divisa, sobre todo en elementos arquitectónicos y se plantea la posibilidad de que la granada fuera empleada como divisa familiar de los Trastámara y sus descendientes. Así parece deducirse de la presencia de la pictura de la divisa en varias empresas personales de parientes que vivieron en el siglo XVI.

PALABRAS CLAVES: granada, divisas, clemencia real, Enrique IV, Reyes Católicos, Catalina de Aragón, Carlos V, Felipe II.

Fecha de recepción: 21-9-2014 / Fecha de aceptación: 24-10-2014

1. Este trabajo se inscribe en el proyecto de investigación Biblioteca Digital $f$ de Oro IV, código FFI2012-34362, financiado por el Ministerio de Economía y Competitividad del Gobierno de España (desde el 1-2-2013 hasta el 31-1-2016). Deseo manifestar mi agradecimiento a Alonso Zamora Canellada, por proporcionarme las fotografías de las ilustraciones 3 y 4 y a José Ramón Martínez de Murguía Larrea por las fotografías de las ilustraciones 8 y 9. 
Enrique IV de Trastámara (Valladolid, 1425-Madrid, 1474), fue rey de Castilla durante veinte años, entre 1454 y 1474. Reinó en un momento en que las monarquías europeas se estaban percatando de la importancia que habían adquirido los símbolos de representación real como proyección propagandística de la imagen del monarca, signos complejos, pero bien conocidos en el entorno cortesano. Comienzan a utilizarlos para representar a la persona (no a la estirpe a la que pertenece el individuo que los ostenta) en todo tipo de soportes: telas bordadas, mayólica, artesonados, escultura ornamental en edificios, joyas, elementos de atuendo en justas y torneos, etc.

Tenemos muestras de las primeras divisas personales de reyes castellanos desde finales del siglo XIV e inicios del XV, en los reinados de Enrique III (1390-1406), que empleó el cordón de San Francisco (Ceballos-Escalera, 1998), y Juan II (1406-1454), que utilizó ristres, escamas y llamas de fuego (Fernández de Córdoba, 2012), además de la denominada Divisa de la Banda Real de Castilla (de gules, una banda de oro con dragantes), perteneciente a la Orden de la Banda, creada por el rey Alfonso XI y convertida en el reinado de Juan II en divisa personal, que empleó a la par que su escudo real (Ceballos-Escalera, 1985: 668-671).

Francisco Gómez de la Reguera, en la obra que dejó manuscrita Empresas de los Reyes de Castilla, que debía de estar terminada hacia 1632, pero que no se imprimió hasta 1991 (incompleta) y en 2011 en una segunda edición completa basada en un manuscrito diferente ${ }^{2}$, ofrece como divisa de Enrique IV de Castilla una empresa que emplea una pirámide por pictura, con el lema "Nisi Dominus frustra». No sabemos en qué fuente pudo inspirarse Gómez de la
Reguera para esta atribución, y no parece muy fundamentada.

En todo caso, de lo que sí tenemos testimonios diversos es de que el rey castellano utilizó una divisa perfecta tal como las concibe la preceptiva posterior sobre emblemática, es decir, compuesta de cuerpo y alma, cuya pictura eran unas granadas enramadas y el lema o mote "Agro dulce» ${ }^{3}$. Además de como divisa completa, con frecuencia aparece la granada aislada como empresa muda identificativa del monarca o bien se representa mediante dos ramos de granado repletos de su fruta rodeando el escudo real.

A esa divisa es a la que dedicamos este trabajo, que tiene por objeto determinar el sentido simbólico atribuido al objeto seleccionado como pictura y el sentido cabal que junto con el mote pudo tener en tiempo del dueño de la divisa. También se dedicará algún espacio a señalar vestigios de la empresa utilizada por este monarca y a constatar que su descendencia siguió utilizando el motivo, para transmitir el mismo mensaje conceptutal o uno diferente, pero manteniendo el «cuerpo» de la empresa: la granada.

Además de cómo divisa, es posible que el rey la emplease también como orden de caballería (Ceballos-Escalera, 1985: 671) como se deduce de la relación del viaje de Jörg von Einghen, joven caballero suabo que vino a España en 1457 al enterarse de que Enrique IV preparaba una incursión contra los moros de Granada, en la que participó. Al finalizar la contienda, este caballero pasó dos meses en la corte, desde donde se dirigió a Portugal. El rey Enrique IV concedió a Einghen y a su amigo Jorge de Ramyden, de Salzburgo:

2. La primera edición es de 1981, por César Hernández, pero es incompleta. Véase la nueva edición de Nieves Pena Sueiro (2011: 139-143).

3. Hemos encontrado descripciones modernas de la divisa donde el mote aparece como "Agridulce es el reinar" (Ceballos-Escalera, 1985: 671) pero no hemos hallado ningún texto de la época que confirme esa fórmulación, y sí en cambio la de "Agro dulce». 
el distintivo de sus órdenes, a saber: de la Española, que es una banda ancha y linda, con placas superpuestas como escamas de pescado, y la otra la banda de Castilla, con una túnica escarlata y una banda dorada de dos dedos de anchura, que pasaba por debajo del blazo izquierdo y bajaba oblicuamente por delante hasta el extremo de la túnica del lado derecho, y desde aquí subiendo por detrás llegaba hasta debajo del mismo brazo izquierdo. La Orden tercera es la de Granada: que es una granada sobre un globo, con un cabo o pedículo y algunas hojas. Nos dio además 300 ducados y un hermoso caballo a cada uno. Así nos separamos honrados, alabados y con provecho de este cristiano rey Enrique, en el año del nacimiento de Nuestro Señor, 1457 (Fabié, 1879: 44-45).

La divisa del rey Enrique IV se empleó en muy diferentes soportes, pero solo quedan accesibles para nosotros aquellos más duraderos: esculpida en piedra, representada en madera, en monedas y pintada en yeserías policromadas.

Como testimonio documental de que el rey la consideraba su divisa, sírvanos un fragmento de las ordenanzas para labrar moneda de vellón dadas por el rey Enrique IV en Madrid, el 22 de mayo de 1462, donde se explicita que en la moneda de un maravedí ha de representarse una granada de las de su divisa:

e por esta my carta ordeno e mando por ley e premática sanción la qual quiero que aya fuerza e vigor de ley [...] que en las dichas mys casas de moneda se labren de aquí adelante las monedas de villón [sic] syguientes: Primeramente hordeno e mando que se labren en las dichas casas de moneda, moneda de maravedís de ley de venyt e quatro granos por marco e de talla en cada marco noventa e seys pyezas e que cada pieza destas sea llamada maravedí e valga por un maravedí, la qual dicha moneda de mara- vedís tenga de un lado un castillo e del otro cavo un león, el qual dicho león tenga una granada de las de mi devysa entre los pies e manos e su orladura llana syn copas algunas de dentro e enderredor del dicho castillo e león en entramas partes de los dichos maravedís fuera de la dicha orladura aya letras que digan ENRICUS QUARTUS DEI GRACIA REX CASTELLE ET LEGIONIS ${ }^{4}$.

Otro testimonio textual, en este caso literario, se lo debemos a Lope de Vega, en cuya obra El castigo del discreto menciona la empresa de Enrique IV:

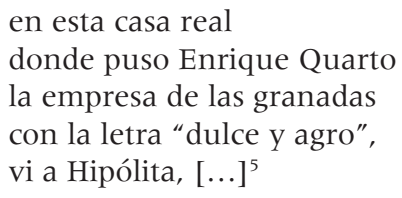

\section{SIMBOLISMO DE LA GRANA- DA Y SENTIDO DE LA DIVISA DE ENRIQUE IV}

Desde la antigüedad, la granada ha tenido muchas asociaciones simbólicas, pues se presta a múltiples creaciones metafóricas vinculadas a su forma y contenido: la culminación de la fruta con una especie de corona, la multitud de granos que oculta, las divisiones internas que se producen mediante la membrana que separa grupos de granos, la corteza fuerte y áspera que contrasta con lo delicado y suave de su contenido, su sabor agridulce [...]. Sin embargo, nos interesan especialmente las interpretaciones que se le dan en España, bastante alejadas de las de la literatura clásica, y que tuvieron amplia difusión en empresas de la familia Trastámara y sus sucesores.

4. Este documento está en el Archivo del Ayuntamiento de Burgos, Sección Histórica: $\mathrm{n}^{\circ \prime}$ 1.315. Empleo la transcripción de Sainz Varona (1982: 249).

5. Edición de Fichter, 1925, vv. 1539-1543, p. 134.

IMAGO, NÚM. 6, 2014, 81-95 
Sebastián de Covarrubias, en su Tesoro de la lengua castellana o española (1611), indica que «La granada puede ser símbolo de una república, cuyos moradores están muy conformes y adunados [congregados], y está adornada con corona, que significa dominio e imperio, porque la granada está coronada con una corona de puntas». Luego cita la empresa de Enrique IV:

\begin{abstract}
Hay una empresa de una granada con el mote "Agrodulce», de que usó el rey don Enrique el Cuarto, dando a entender que el rey ha de tener de todo, usando de justicia y de clemencia, templando una con otra.
\end{abstract}

Es la literatura emblemática la que más nos ayuda a comprender el sentido con el que se utiliza la granada en la empresa de Enrique IV y otros monarcas. Juan de Borja, en la segunda edición ampliada de sus Empresas morales (1680), en la empresa 198 (pp. 402-403) [fig. 1], con el lema «Et dulciter acre temperabis» expone que hay que huir de los extremos buscando el equilibrio entre lo que nos gusta y lo que nos es provechoso y que esta dificultad la tienen los que gobiernan para hallar el punto medio entre la justicia y la clemencia. Ellos han de huir de los extremos de la crueldad y la flojedad, templando la justicia con misericordia y la clemencia con la justicia. Concluye Borja: «Este agro dulce, dijo Aristófanes, que se hallaba en la granada ${ }^{6}$.

Fray Antonio de Lorea, en su David pecador (1674) en la empresa 21 (lib. II, cap. VI, 345-360), con lema "Clementiae pondus» (el peso de la clemencia), asocia la granada a las virtudes reales, pues esta fruta presenta un paralelismo con el estado o la república: la multitud de sus granos representa los ciudadanos, que esperan la protección de su señor; las membranas internas son las que separan y ordenan las distintas clases sociales; la corteza dura muestra la protección real y el cuidado que el Príncipe ha de poner para

6. No he logrado encontrar esa fuente en Aristófanes.

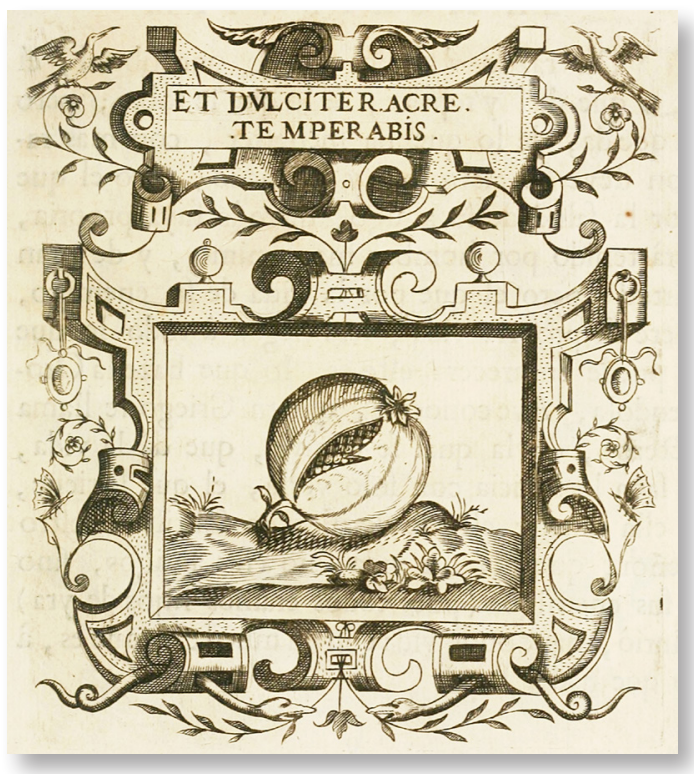

Fig. 1. Juan de Borja, Empresas morales (1680), emp. 198

amparar a los suyos; y sobre el fruto aparece una corona. Cuando el fruto madura, la corteza se abre proporcionando comodidad a los granos para que no estén apretados, enseñando al monarca mudamente el arte de gobernar, pues indica que no ha de gozar de comodidades a costa del malestar de sus súbditos, o ellos, por sus propios medios lo harán, atentando contra el equilibrio de la república. A pesar de lo que pueda esperarse por el mote de esta composición emblemática de Lorea, el farragoso discurso que sigue no da explicación suficiente de por qué vincula la granada con la clemencia.

Muy esclarecedor, en cambio, es el testimonio que da sobre la divisa del rey Enrique IV uno de los autores de libros de emblemas más interesante para nosotros, Juan de Horozco, en sus Emblemas morales (Segovia, 1589), libro III, emblema XXX, que corrobora la interpretación que hemos citado de su hermano Sebastián de Covarrubias [fig. 2]. La pictura del emblema de Horozco reproduce el escudo de armas de Castilla y León del rey Enrique flanqueado por dos ramas de 


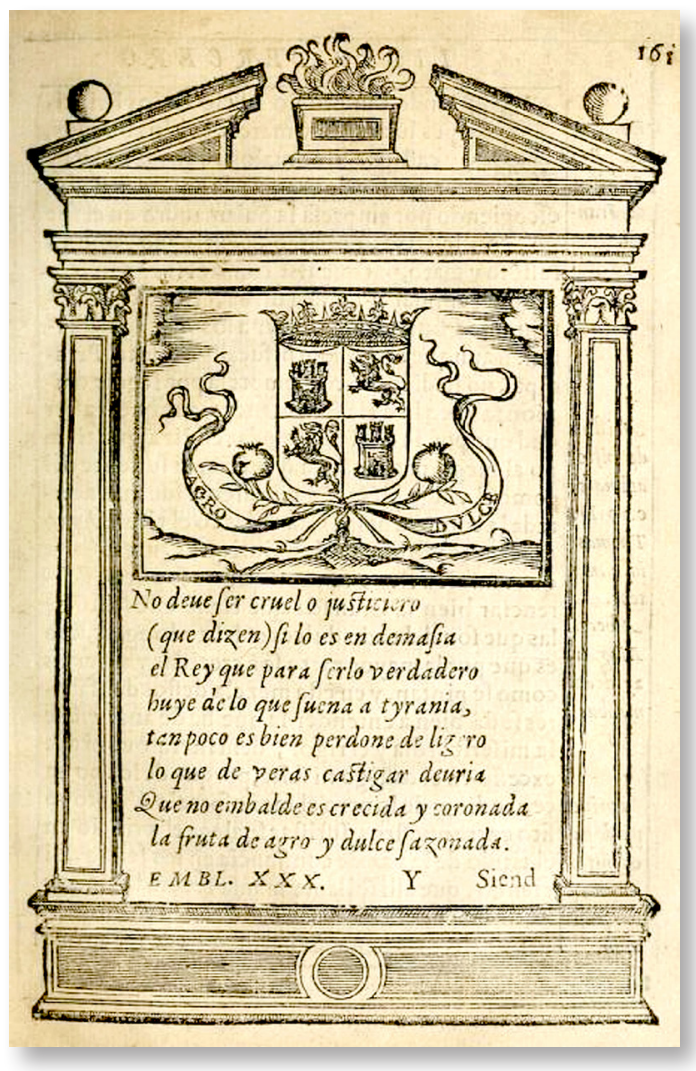

Fig. 2. Juan de Horozco, Emblemas morales (1589), libro III, emb. 30

granado con su fruto y hojas a cada lado y una filacteria con el mote: "Agro dulce». El epigrama del emblema de Horozco es una octava:

No debe ser cruel o justiciero (que dizen) si lo es en demasía el rey, que para serlo verdadero huye de lo que suena a tyranía; tampoco es bien perdone de ligero lo que de veras castigar debría. Que no en balde es crecida y coronada la fruta de agro y dulce sazonada.

Horozco explicita con mucho detalle en la declaración en prosa que sigue al epigrama el sentido de la divisa del rey Enrique
IV. Por los dos sabores (agrio y dulce) de la granada se da a entender la mezcla de misericordia y rigor con que el príncipe ha de regir a sus vasallos, de manera que ni haya exceso en el castigo ni falta:

\begin{abstract}
Siendo tan propio oficio de los Príncipes hacer bien y mercedes a los buenos, y castigar a los malos tuvo razón el Rey Francisco de Francia de preciarse de esto, escogiendo por empresa la salamandra en el fuego, con la letra, NUTRISCO \& EXTINGUO, que es «sustento y mato", porque así como el fuego sustenta aquel animal y mata a otros, el rey debe sustentar los buenos y destruir a los que no lo fueren. Y aunque el propósito fue digno de tal príncipe [...] a mi parecer fue más acertada la empresa de las granadas con el título AGRO DULCE, que uso el rey don Enrique Cuarto [...] y en esta mezcla de estos dos sabores se da bien a entender la que ha de haber entre la misericordia y el rigor, de manera que ni haya exceso en el castigo ni falta, porque de lo uno nace el odio, y de lo otro el menosprecio ${ }^{7}$.
\end{abstract}

Podemos deducir, siguiendo a los emblematistas, que la divisa de Enrique IV es una declaración de que la tarea primordial del monarca es saber aplicar prudentemente la justicia y la clemencia.

\section{VESTIGIOS DE LA DIVISA DE ENRIQUE IV}

Nos quedan vestigios de la divisa de Enrique IV en elementos arquitectónicos (esculpida en piedra, en madera, pintada en yeserías), en monedas, guiones o estandartes.

Aunque el testimonio de Juan de Horozco date de un siglo después de fallecido el rey Enrique, avala la buena interpretación que hace de la divisa su cercanía y buen conocimiento de lugares donde vivió el

7. Juan de Horozco, Emblemas morales, lib. III, emblema XXX, fol. 161r-162v.

IMAGO, NÚM. 6, 20I4, 8I-95 
monarca y donde en el momento en que Horozco escribe todavía existían edificios donde las armas y la empresa del rey podían apreciarse -algunos de ellos borrados ya hoy, desgraciadamente-. Como es sabido, el emblematista vivió y publicó su libro de emblemas en Segovia, ciudad predilecta del monarca, y sabemos que conocía bien el palacio de San Martín de esa ciudad, en cuyos patios se mostraban los escudos de armas de Enrique IV y de su esposa doña Juana de Portugal. Este palacio Real de san Martín fue fundación de Juan II para aposento de su hijo, el príncipe don Enrique ${ }^{8}$, que lo empleó habitualmente como morada cuando estaba en la ciudad (mientras que el Alcázar se usaba para actos de representación de la corte). En 1456 se llevaron a cabo notables obras de remodelación en el palacio. Fue habitado por los Reyes Católicos en sus estancias en Segovia, a la vez que los aposentos de El Parral, del palacio de Santa Cruz y del Alcázar. Hoy ha desaparecido su estructura original (al ser segregado en partes y haber sufrido el conjunto una larga historia de reedificaciones $)^{9}$ y hemos perdido vestigios de las armas o de la divisa del monarca castellano.

En la misma ciudad de Segovia, a las afueras, en lo que fue la quinta de caza El Campillo, Enrique IV mandó construir en 1455 un palacio de recreo, que luego donó a los franciscanos, y que hoy conocemos como monasterio de San Antonio el Real. Ya en época de los Reyes Católicos, el 12 de abril de 1468, el monasterio fue cedido a las clarisas y se mantuvo como convento de clausura. Posiblemente gracias a eso todavía podemos ver hoy en él residuos de las ar- mas de su fundador y su divisa en yeserías, artesonados y tallas en piedra en relativo buen estado, como por ejemplo:

- La portada de la iglesia conserva el escudo de armas del rey Enrique IV, y en él pueden apreciarse muy bien las granadas enramadas [fig. 3]. Así mismo, el arco conopial de la entrada está rodeado de ramos con granadas.

- También hallamos vestigios en la capilla mayor.

- El lado oeste del claustro está ocupado por el refectorio, en el que un púlpito destinado a la lectura durante las comidas, está decorado con las granadas de la divisa del rey.

- El techo está decorado con alfarje agramillado, con la heráldica del monarca en las tabicas, con las granadas.

Otro lugar que aún nos permite ver restos de la divisa de Enrique IV es el Monasterio jerónimo de Santa María del Parral, a la orilla del río Eresma, extramuros de Segovia, en lo que se conoce como "La alameda». Fray Gabriel de Talavera y fray José de Sigüenza, historiadores de la Orden, atribuyen a Enrique IV la construcción del mismo, iniciada en el año 1447, si bien bajo el nombre de Juan Pacheco (marqués de Villena), su camarero mayor, porque, según éstos, no parecía oportuno que siendo don Enrique todavía príncipe levantara edificios. Ya siendo rey, impulsó las obras, y mandó que le construyeran unos aposentos a poniente. Las obras continuaron hasta 1503 (ya muerto el monarca) y en esos aposentos se alojó en ese año, en agosto, la reina Isabel la Católi-

8. Según Diego de Colmenares, en su Historia de la insigne Ciudad de Segovia, cap. XXIX, 3, p. 577, en 1429 el Rey Don Juan II puso casa al príncipe Don Enrique en Segovia, donándole la ciudad: "Aunque tan ocupado en guerras puso el rey casa al príncipe don Enrique año mil y cuatrocientos y veinte y nueve en nuestra ciudad, como más a propósito, de la cual adelante le hizo donación y gracia con toda su jurisdicción: causa de que este príncipe la tuviese tanto amor y nombrase siempre su ciudad».

9. Ver José Miguel Merino de Cáceres, publicado el 26/7/2005 «El Palacio Real de Segovia, un monumento que desaparece», <http://www.salvarpatrimonio.org/cronicas/palacio-real-segovia.html>, que indica que de lo que fue el Palacio Real de San Martín, hoy solo se conserva (y no en su integridad) lo que fueron las «casas de la reina». 


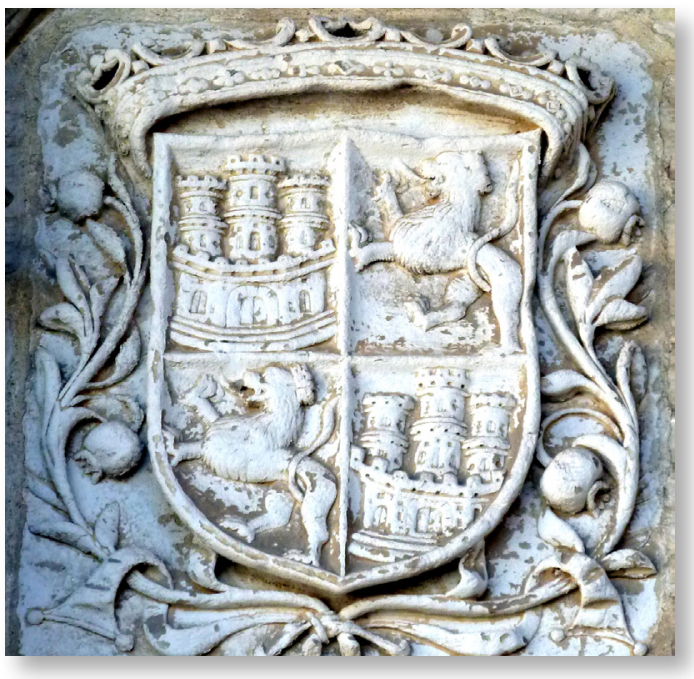

Fig. 3. Monasterio de San Antonio el Real (Segovia). Armas de Enrique IV en portada de la iglesia

$\mathrm{ca}^{10}$. Aunque no es fácil acceder a partes de este monasterio de clausura, hemos podido obtener algunas imágenes de rastros o indicios de la divisa de Enrique IV en la portada exterior del monasterio del Parral, sobre dos puertas del primer claustro y en una tabica de un artesonado trasladado, de la celda del prior. Por limitaciones del número de ilustraciones, no podemos ofrecerlas aquí.

También vivió Juan de Horozco en Cuéllar, de donde fue arcediano, y en la puerta de acceso al castillo de dicha ciudad segoviana podemos todavía encontrar muy claramente la empresa del rey Enrique, con su lema incluido: "Agro dulce» tallado en letras góticas [fig. 4].

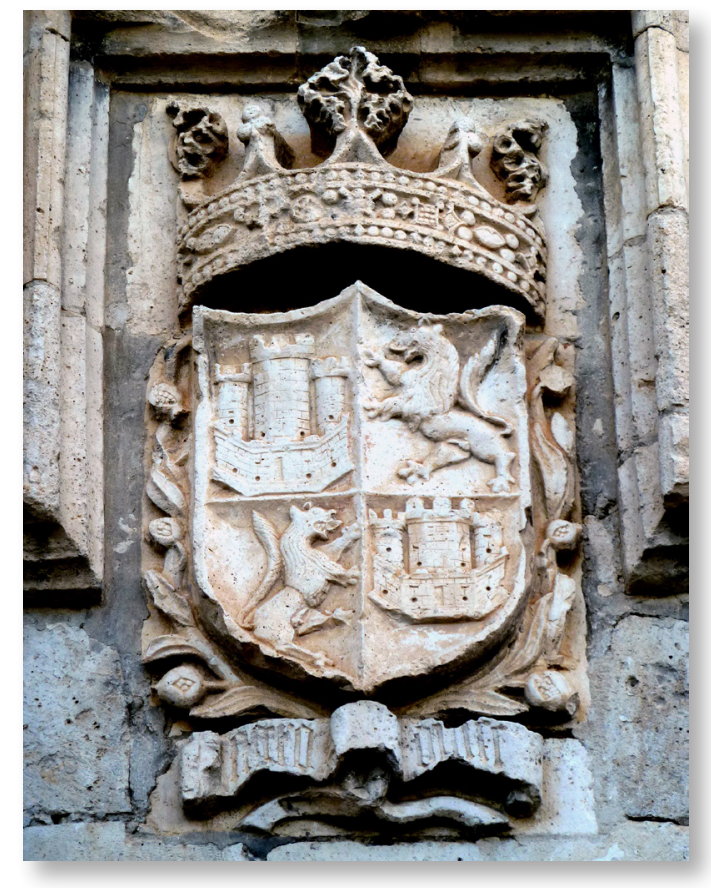

Fig. 4. Castillo de Cuéllar (Segovia). Escudo y divisa de Enrique IV

El escudo de Enrique IV con sus granadas podemos verlo también en la fachada de la Casa del Cordón de Burgos.

Así mismo, en las monedas de maravedí del reinado de Enrique IV, realizadas en varias cecas, encontramos su distintivo de la granada, siguiendo sus instrucciones dadas en la Ordenanza de 1462 a que hemos aludido arriba (Sainz Varona, 1982: 249).

La divisa del rey se encuentra no solo vinculada al escudo de armas del monarca,

10. En la página web del propio Monasterio, <http://www3.planalfa.es/msmparral/parral/historia.htm> [01-072013], en el apartado «Historia y Arte», se describe: «Dos arcos planos, muy de la moda del momento, dan paso a la nave. En sus dovelas los ramos de granados aluden a la divisa de las armas de Enrique IV». En este trabajo se indica sobre el claustro de la hospedería: «Este claustro, al que se entraba por la puerta del fondo del pórtico, tenía la función de acoger a los huéspedes que llegaban al monasterio. Sigüenza escribe que fue construido por Enrique IV 'donde se venía a recrear y comunicar con los religiosos', y las habitaciones estaban decoradas con artesonados polícromos. Ardió en julio de 1566 y fue reconstruido. Como tal claustro, destinado a seglares, parecía el patio de una casa noble segoviana, con sus pilares de piedra caliza en la parte baja y galería de madera en la alta. Hoy sólo quedan los pilares y el centro ha sido convertido en estanque (1974). Desde el pórtico, por puerta adintelada de granito, timbrada con el escudo de Enrique IV, entramos al claustro de la Portería, pequeño y recoleto. Consta de cuatro arcos, de idéntica factura que los del pórtico, lo que hace suponer que ambos fueron levantados a principios del XVI. El artesonado es de época reciente, al igual que el escudo de la Orden, no así los de Enrique IV que campean sobre las puertas de paso al claustro de la Hospedería y Principal».

IMAGO, NÚM. 6, 2014, 8I-95 
sino exenta (una sola granada, o una rama de ellas, o varias ramas entrecruzadas). Como es sabido, el color asociado a una divisa personal también es significativo en la época, y en este caso era el verde (ramas) y el rojo (granada).

\section{DIVISA PERSONAL - DIVISA FAMILIAR}

Como es sabido, una divisa o empresa ${ }^{11}$ era expresión personal de un ideal, una aspiración heroica o una intención elevada del individuo que la ostentaba, y por lo tanto inapropiada para ser usada por alguien que no fuera la persona a la que únicamente perteneció; así lo defiende Girolamo Ruscelli (1556), que recalca la naturaleza individual de las empresas, e indica que no han de ser heredadas por hijos, hermanos u otros parientes del que la ostentó, ya estuviera vivo o muerto:

\begin{abstract}
Le imprese non debbono per alcun modo essere ereditarie, sì come sono l'Arme; né debbono usarsi da i figliuoli o da i nepoti, né da altri discendenti doppo la morte de' padri, degli avoli, o de gli altri maggiori loro. Anzi né ancor vivendo i padri si convien che i figliuoli usino l'Imprese loro ${ }^{12}$.
\end{abstract}

Sin embargo, lo que se especulaba teóricamente en el siglo XVI italiano, no siempre se observó en la Castilla del siglo XV. Los Reyes Católicos utilizaron la banda de Juan II, así como la granada de Enrique IV, como divisas familiares en bordados de atuendos, joyas, ornamentación de libros y otros ob- jetos, más por su significado emblemático (el que le daba Enrique IV) que como símbolo de la conquista de la ciudad de Granada -pues su uso se inició antes de 1492(Menéndez Pidal, 2005: 124-128; Narganes Quijano, 2008). Según Diego Clemencín (que transcribe un documento del archivo de Simancas (Contadurías, $1^{a}$ época, núm. 106), en 1477 Isabel la Católica enriqueció su corona rica con perlas que mandó quitar de varias joyas, entre otras una granada de oro que le había regalado el rey Fernando:

\begin{abstract}
E mas se puso en la dicha corona un diamante grande punta e un rubí e doce perlas, que se quitó todo de la granada de oro que había dado el Rei nuestro señor a la Reina nuestra senora. En la granada estaban catorce perlas y dellas se pusieron en la corona doce $\mathrm{e}^{13}$.
\end{abstract}

Tradicionalmente se ha dado un sentido territorial a la granada, tras la conquista de la ciudad del mismo nombre en 1492. Como es sabido, al escudo de los Reyes Católicos (cuya forma se había acordado en diciembre de 1474), se le incorporó un entado en punta con una granada, y suele creerse que fue tras la entrada triunfal en Granada el 2 de enero de 1492. Sin embargo, como indica Pardo de Guevara (2008: 83), no hubo, por lo que parece, ninguna disposición legal relativa a su nacimiento como emblema propio del reino recién conquistado, ni mucho menos respecto a su rápida incorporación a las armerías reales. El primer testimonio parece que está en un sello de placa de Fernando el Católico sobre un documento fechado en Zaragoza a fines

11. divisa y empresa son una misma cosa. El que sigue la tradición francesa, prefiere la denominación de divisa, y quienes siguen la italiana, hablan de empresa. Véase para detalles Ann Rolet (2007: 54).

12. Discorso di Girolamo Ruscelli intorno all'inventioni dell'Imprese, dell'Insegne, de'Motti, et delle Livree. Incluido en: Paolo Giovio, Ragionamento[..]. (1556: 189-190).

13. Relación de las piedras e perlas que la Reina nuestra señora mandó poner en la corona de oro contenida en el pliego primero deste libro del cargo de 77, las cuales puso e asentó en la villa de Ocaña, estando allí su alteza en dicho año, García Gomes platero de Valencia, que hizo la dicha corona; las cuales piedras e perlas mandó quitar su alteza de ciertas joyas de su cámara segund de yuso será todo declarado. En: Memorias de la Real Academia de la Historia: 1821, Volumen 6, Madrid, Imprenta de Sancha, 1821, 336-337. 
de agosto del mismo año 1492. Pese a ello, su incorporación no se consolidaría debidamente hasta las Ordenanzas dictadas en 1497 en Medina del Campo, donde se tomo el acuerdo de la acuñación de los llamados excelentes de la granada.

Un interesante testimonio temprano de la importancia que se otorgó a la conquista del reino nazarí, podemos verla en un grabado xilográfico que debió de realizarse en 1493. El rey Fernando el Católico, representado como "rex hyspania", aparece sosteniendo por el tiracol dos escudos de armas: uno con las armas de Castilla y otro en el que solo se ostentan ocho granadas [fig. 5]. El taco xilográfico fue utilizado en una de las muchas ediciones de la carta de Colón (la impresa el 21 de abril de 1494 en Basilea) ${ }^{14}$ enviada a los Reyes Católicos para dar cuenta de su descubrimiento; concretamente, el grabado era la portada de una obra que formaba conjunto con esa edición de la carta de Colón: Carlo Verardi, In laudem Serenissimi Ferdinandi Hispania[rum] regis Bethicx $\theta$ regni Granatae obsidio, victoria, e triu[m]phus. Et De insulis in Mari Indico nuper inuentis ([Basel]: I.B. [Johann Bergmann, de Olpe], 1494).

Como apuntábamos más arriba, el uso que hicieron los Reyes Católicos de la divisa de la granada trasciende la simple representación emblemática del reino islámico del sur de la Península Ibérica, y creemos que puede tener un significado más complejo, ya que podemos observar que los reyes lo emplean, en etapas tempranas sobre todo, a la vez que su divisa del yugo y las flechas, que como ya explicamos en otro trabajo tiene un significado único y dual a un tiempo $^{15}$.

\section{In laudem Bereniffi mi FerdinandiHif paniaze regis/Bethi= cæ \& regni Granatä /obfidio/victoria / \& triúphus/ Et de Infulisin mari Indico nuper inuentis}

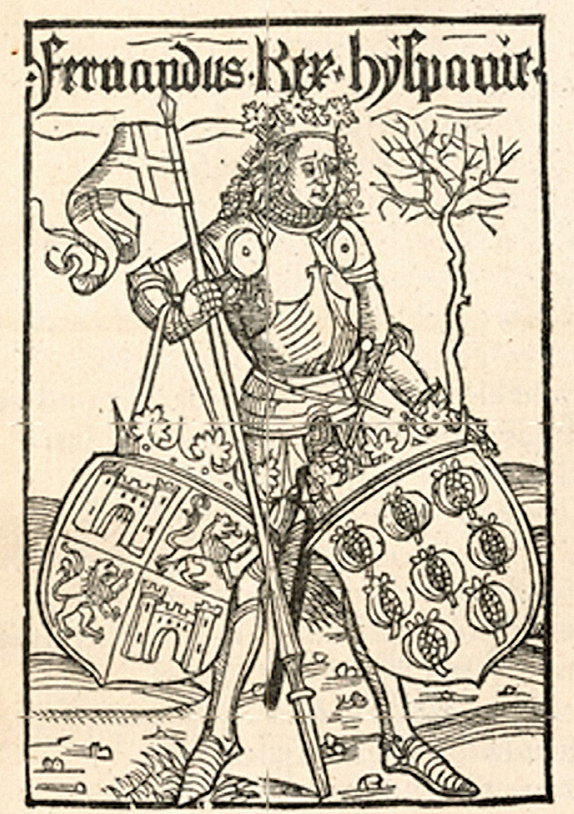

Fig. 5. Portada de: Carlo Verardi, In laudem Serenissimi Ferdinandi Hispania[rum] regis Bethicae of regni Granatae obsidio, victoria, o triu[m]phus (1494)

Así, tendríamos que con el yugo de Fernando, símbolo de castigo y doma para los súbditos rebeldes (la nobleza levantada contra Isabel en la guerra de sucesión dinástica entre 1474 y 1479) se avisa al receptor que quienes no se sometan por las buenas (bajo el yugo) recibirán las saetas (signo bélico)

14. Al llegar a Lisboa en marzo de 1493, Colón envió una carta a los Reyes Católicos dando cuenta del descubrimiento: creía haber llegado a la Provincia de Catayo (China) en el Índico. La carta se publicó primero en Barcelona, e inmediatamente se produjeron múltiples ediciones que se convirtieron enseguida en "bestsellers» por toda Europa. Solo en 1493 se produjeron once ediciones. La edición que nos interesa fue publicada el 21 de abril de 1494 en Basilea. Contiene los mismos grabados xilográficos que la primera edición ilustrada de la carta, impresa en Basilea el año anterior. Esta edición tiene de particular que se publica junto con otro texto, conocido como Historia Baetica, drama en prosa de Carolus Verardus (Carlo Verardi) en que celebra la reconquista de Granada por los Reyes Católicos, y su portada es el grabado que nos ocupa.

15. Lopez Poza (2012: 14).

IMAGO, NÚM. 6, 2014, 8I-95 


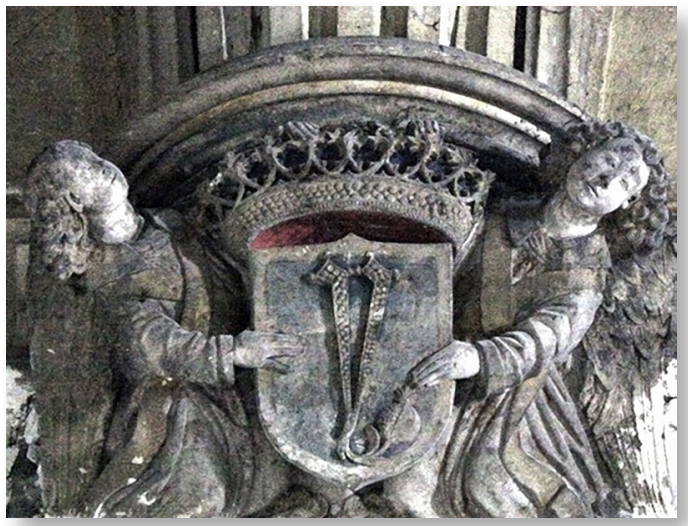

Fig. 6. Sala capitular de Santa Cruz la Real, Segovia

-por las malas-; de una u otra forma, tanto da de grado como por la fuerza (TANTO MONTA), los reyes ejercerán su poder, que puede mostrar misericordia o rigor (AGRO DULCE) la granada- haciendo merced y favoreciendo a los que lo merezcan y castigando a los que se obstinen en enfrentárseles.

Es sabido que el escudo de los Reyes Católicos aparece en ocasiones tempranas de su reinado en conjunción con unas ramas de granado y su fruto (véase más abajo el ejemplo de la Sala Gótica de la Casa del Cordón de Vitoria). Y la granada familiar se emplea de forma complementaria o paralela a sus divisas personales, como vemos en el claustro del monasterio de Santo Tomás de Ávila, y en la portada del colegio de San Gregorio de Valladolid.

Podemos ver la letra Y de la inicial del nombre de Ysabel, unida a la granada como divisa familiar, sostenida por dos ángeles tenantes en el arranque de los nervios de la bóveda de la sala capitular de Santa Cruz la Real, Segovia [fig. 6].

En el precioso artesonado mudéjar polícromo del claustro alto del Monasterio de San Juan de los Reyes, de Toledo, se ostentan como motivos las iniciales de Ysabel y Fernando, las armas Aragón, Sicilia, León y Castilla. Al escudo de Castilla y al de León lo rodean ocho granadas abiertas mostran-

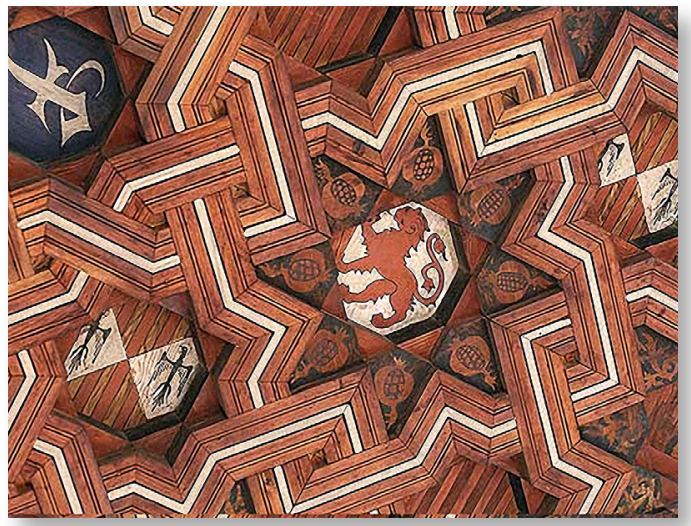

Fig. 7. Artesonado del claustro alto, Monasterio de San Juan de los Reyes (Toledo)

do su fruto en cada una de las puntas de la estrella que forma la tracería [fig. 7]. En el exterior de este mismo monasterio, entre las figuras de bulto colocadas en las pilastras de refuerzo del ábside, en la cabecera de la iglesia, se representa a varios heraldos; podemos ver en relieve, en la parte inferior de la cota de armas, junto a los escudos de los diversos reinos, una granada enramada.

Vestigios menos conocidos también corroboran que la granada era empleada por los reyes como divisa. Así lo advertimos en la ya mencionada Casa del Cordón de Vitoria, donde encontramos estos elementos:

- la clave central de la bóveda estrellada de la Sala Gótica (fechada entre 1478 y 1482) presenta el escudo con las armas de los Reyes Católicos, que sólo se diferencia del empleado por Enrique IV (como se ostenta en el Monasterio de San Antonio el Real de Segovia) en que se han añadido a las de Castilla las armas del rey Católico y el águila de San Juan. Se mantienen las granadas enramadas en la misma forma en los dos escudos (rodeando la parte inferior) [fig. 8].

- En la bóveda de la Sala Gótica hay otras claves en donde se cruzan los nervios, que muestran: 


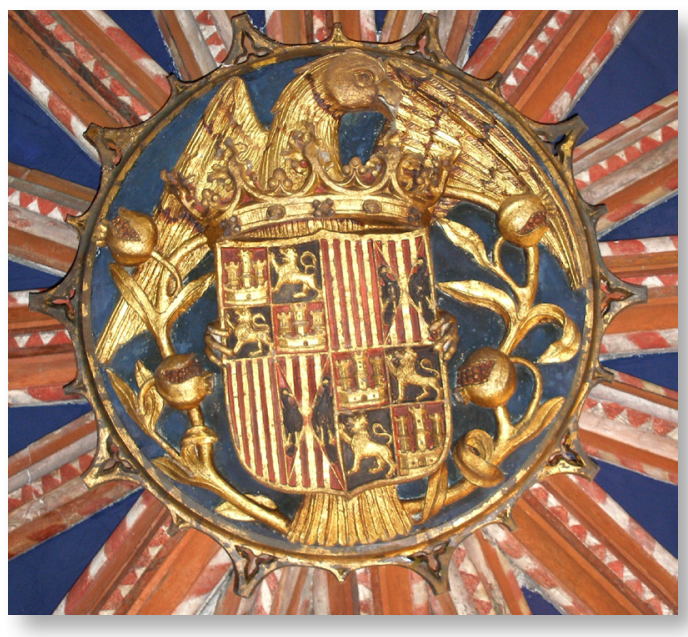

Fig. 8. Escudo Reyes Católicos en la clave central de la bóveda estrellada de la Sala Gótica. Casa del Cordón (Vitoria)

- Las flechas de la divisa de Ysabel (hacia el lado sureste)

- Yugo y coyundas de Fernando (hacia el lado noreste)

- En una ménsula del lado noreste, se representa un león que porta una letra Y griega de Ysabel, unida a dos granadas [fig. 9].

- En otra ménsula del lado sureste, un león porta una letra $\mathrm{F}$ entre las garras, unida también a dos granadas.

Así mismo, en el Monasterio de Santo Tomás de Ávila hay huellas del uso de la granada como divisa; por ejemplo, sobre la puerta que está bajo un arco conopial en el acceso desde el claustro a la escalera que da al coro de la iglesia, se pueden ver ocho granadas enramadas.

Podemos ver la granada también junto a las divisas personales de los reyes en el códice conocido como Cancionero de Pedro

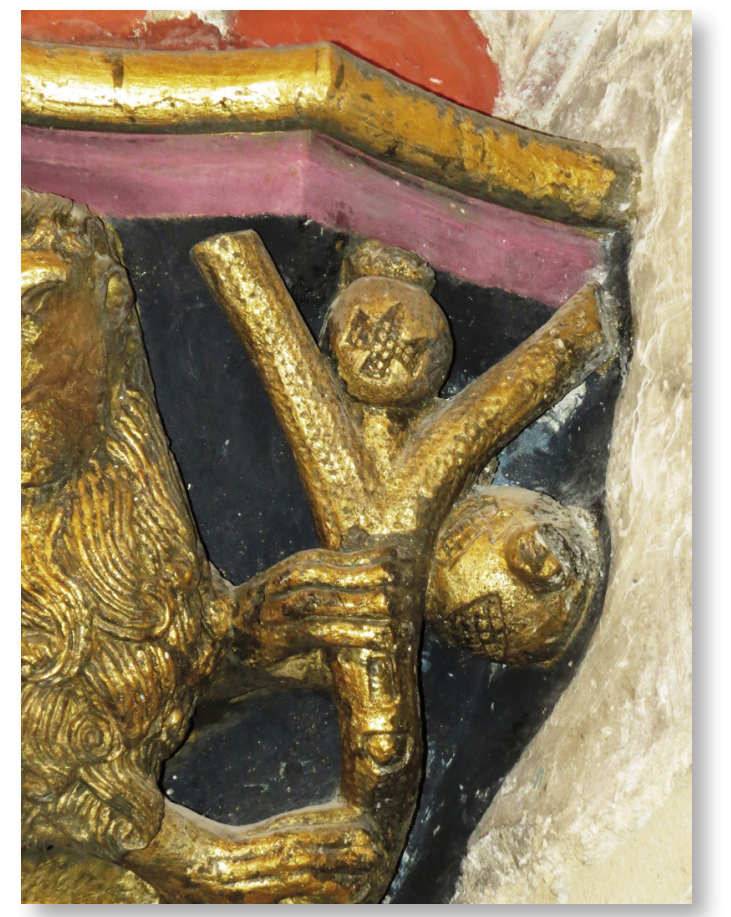

Fig. 9. Sala Gótica, Casa del Cordón (Vitoria). Ménsula lado Noreste

Marcuello y también como Devocionario de la Reyna $D^{a}$ Juana a quien llamaron la Loca' ${ }^{16}$, cuyas composiciones y miniaturas han sido fechadas entre 1482 y 1502. El códice es una recopilación de diversas obras poéticas compuestas por Pedro Marcuello y ofrecidas a los príncipes Felipe el Hermoso y Juana (la Loca) en 1502.

Descendientes de los Reyes Católicos ostentaron también la divisa de la granada. Así, su hija Catalina de Aragón (1485 - 1536), reina consorte de Inglaterra, usó la granada como parte de su escudo de armas y divisa personal, y también la utilizó su hija, la reina María Tudor. Hay muchos testimonios de ello en grabados, pinturas, bordados, encuadernaciones de libros, pero no

16. Durante varios siglos se conservó en la Real Cartuja de Nuestra Señora de Aula Dei, de Zaragoza, hasta que con la desamortización eclesiástica del siglo XIX y la exclaustración de los frailes, el manuscrito se perdió. Apareció en 1857 en el Museo Condé de Chantilly (Francia), por adquisición del duque de Aumale, Henri d'Orléans. Este hermoso códice está ilustrado con 58 miniaturas de extraordinario interés. Véase para más detalle Marín Pina, 1990. 


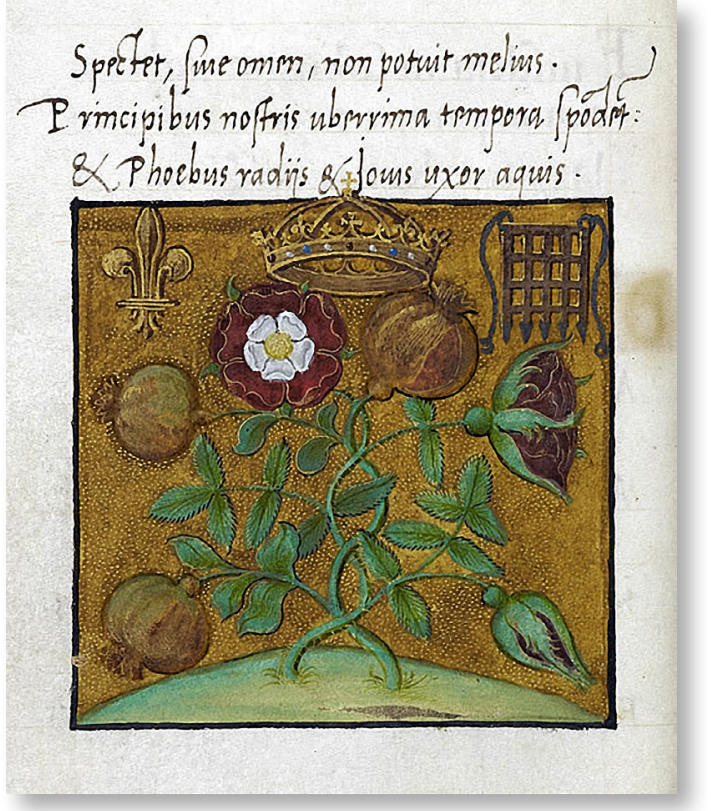

Fig. 10. Portada del manuscrito Sir Thomas More writing on the coronation of Henry VIII. British Library (Cotton Ms. Titus D iv, ff.12v-13)

podemos incluirlas por la limitación del número de ilustraciones permitida en esta publicación. Solo aportaremos como testimonio una imagen [fig. 10] que es la portada de un manuscrito conservado en la British Library que contiene una oda escrita por Tomás Moro en alabanza de Enrique VIII y su esposa Catalina de Aragón en el día de su coronación (24 de junio de 1509) ${ }^{17}$. Podemos ver la divisa del rey (la rosa Tudor) con la de la reina (la granada Trastámara). Según el cronista Edward Hall, al día siguiente de la coronación se celebró un torneo; los caballeros llevaban atuendos que mostraban, sobre terciopelo blanco, rosas de oro de la casa Tudor y, sobre terciopelo verde, granadas bordadas en oro que se asociarían a la casa de Trastámara ${ }^{18}$.

Podría decirse, pues, que la granada se empleó como divisa distintiva de los Trastámara, e incluso tal vez, antes de ellos, fuera usada por otros monarcas del territorio ibérico ${ }^{19}$.

No sólo los familiares directos de los Trastámara hicieron uso del motivo de la granada, sino allegados o vinculados a la familia por parentesco indirecto. El emperador Maximiliano de Austria usó como divisa una granada, que había recibido como regalo de sus consuegros, los Reyes Católicos, como recoge la obra de Fugger (1555: 314) y la de su continuador Birken (1668 apud Menéndez Pidal, 2005: 126). Su divisa era una rueda de seis radios, con un globo del imperio en la parte superior y una granada en la inferior; con el lema: "Per tot discrimina», palabras de la Eneida (per tot discrimina rerum / tendimus in Latium AEN. I, 204-205). El emperador aparece sosteniendo una granada en la mano en dos retratos bien conocidos de Durero, de 1519, uno conservado en el Kunsthistorisches Museum (Viena) y el otro en Nürnberg, Germanisches Nationalmuseum ${ }^{20}$.

El nieto de los Reyes Católicos, Carlos V, es representado en un grabado xilográfico de 1519 como rey de España y candidato al imperio, con la granada en la mano: Maestro de Petrarca -Hans Weiditz-, Carlos $V$ como rey de España y candidato al imperio,

17. Sir Thomas More writing on the coronation of Henry VIII. Signatura: Cotton Ms. Titus D iv, ff. $12 \mathrm{v}-13$.

18. 1509, The coronations of Henry VIII and Katharine of Aragon <http://englishhistory.net/tudor/h8crown.html $>20-$ 8-2013.

19. Capaccio (1592, cap. LXXXV: 137-138) indica que Fernando I de León (1016-1065) ya tenía una empresa con el lema "Vos mentís» y con la imagen de una granada: "Ferdinando Primo, quando sotto pretesto della Moglie Santia, occupò il Regno di Leon; e per mezzo della Madre Eluira, conseguì il Contado di Castiglia, fraudato da vn Nobile Granatino, con questo proposito, fè l'Impresa del Granato, col motto, vos MENTIS, trattandolo di perfida fede, e dicendo che mentiua in bella apparenza, essendo d'animo disleale».

20. Seguramente, a quienes comentan posteriormente la empresa de Maximiliano (por ejemplo, Typotius: Symbola divina $\theta$ humana, ponrificium, imperatorum, regum -1601-) les faltó la clave de interpretación que le daban los Trastámara, que hubiera contribuido a una mejor comprensión del sentido de la empresa. 
Madrid, Biblioteca Nacional, Iconografía Hispana, 1709-1. Igualmente porta una granada en la mano en el retrato xilográfico coloreado del joven rey realizado por Hans Weiditz, conservado en el British Museum, Londres (número 1862,0208.55), en el cual podemos ver en la parte superior el escudo de armas de los reinos españoles, así como las divisas de sus abuelos: el yugo, las flechas y ramas de granado con su fruta.

También usó la granada Felipe II (bisnieto de los Reyes Católicos) en una de sus empresas, la que lleva el mote тот ZOPYRO (Tantos Zópiros), y como pictura muestra dos cetros cruzados en aspa a través de una corona sobre una granada abierta ${ }^{21}$. Al parecer alude a una anécdota atribuida al rey Felipe II, al que un día preguntaron de qué desearía él tener tanta cantidad como de pepitas la granada. Él respondió que quería tantos Zópiros; es decir, tantos amigos fieles. Alude a un episodio relatado por Heródoto acerca de Zópiro, que desempeñó un papel decisivo en la toma de Babilonia por parte de Darío I en diciembre de 522 a. C. Zópiro convenció a Darío para que le permitiera cortarse la nariz y las orejas, herirse $y$, fingiendo ser fugitivo del rey persa, consiguió entrar en Babilonia y convencer a los usurpadores del trono de que había sido víctima de Darío, que estaba sitiando la ciudad desde hacía mucho tiempo, ya desesperado. Le creyeron, y con el tiempo ganó la confianza de los asediados, que le confiaron las llaves de la ciudad, y este noble persa abrió las puertas al ejército para que rescataran Babilonia de los intrusos.

\section{CONCLUSIONES}

Hemos podido constatar que los libros de emblemas ofrecen valiosa información para una correcta interpretación del sentido que tenían las divisas que emplearon monarcas pretéritos. Así mismo, hemos podido observar que en estas divisas los Trastámara y sus descendientes de la casa de Habsburgo han seguido una tradición que, al menos en España, se observa con cierta frecuencia, y es que una empresa personal puede ser reutilizada por los familiares, especialmente el cuerpo de la empresa. La polisemia propia de las imágenes simbólicas permitiría emplear la pictura con el mismo sentido o con otro, asociado a diversos lemas.

Se hace preciso continuar averiguando más sobre las empresas de los reyes de los diversos reinos españoles para tener un panorama completo y poder obtener conclusiones firmes sobre usos y costumbres peculiares de las empresas en España.

\section{BIBLIOGRAFÍA}

BIRKEN, S. VON [1668]. Spiegel der Ehren des Hochslöblichsten Kayser- und Königlichen Erzhauses Österreich order Ausführliche Geschicht Schrift von Desselben... Nürnberg.

BORJA, J. DE [1680]. Empresas morales, Bruselas, Francisco Foppens.

CAPACCIO, G. C. [1592]. Delle imprese; in tre libri diuiso: nel primo del modo di far l'impressa ... :nel secondo tvtti ieroglifici, simboli ... nel terzo nel figvrar degli emblemi di molte cose naturali per l'imprese si tratta, In Napoli : ex officina Horatij Salviani : appresso Gio. Giacomo Carlino o Antonio Pace.

Ceballos-Escalera y GILA, A. [1985]. «Las divisas en la heráldica castellana», Hidalguía XXXIII, 665-688.

- 1998]. "Un oficio bajomedieval desconocido: el alférez mayor del pendón de la Divisa del Cordón de San Francisco", Banderas. Boletín de la Sociedad Española de Vexilología, 69, 6-9. 
COlMenares, D. DE [1637]. Historia de la insigne ciudad de Segouia y conpendio de las historias de Castilla, En Segouia: por Diego Diez, a costa de su autor. 2 vol.

FABIÉ, A. M. [1879]. Viajes por España, de Jorge de Einghen, del Barón León de Rosmithal de Blatna, de Francisco Guicciardini $y$ de Andrés Navajero. Traducidos, anotados y con una introducción por Antonio María Fabié, Madrid, Librería de los Bibliófilos, Fernando Fe.

Fernández DE CórdobA Miralles, A. [2012]. "Las divisas del rey: escamas y ristres en la corte de Juan II de Castilla», Reales Sitios, 191, 22-37.

FUGGER, H. J. [1555]. Wahrhaflige Beschreibung... der aller edelsten... geschlechten der Christenheit, des Habspurgischen und Österreichischen gebluets.

Giovio, P. [1556] Ragionamento di Mons. Paolo Giovio sopra $i$ motti $\theta$ disegni d'arme $\theta$ d'amore che communemente chiamano imprese. Con vn discorso di Girolamo Ruscelli intorno allo stesso soggetto, In Venetia, appresso Giordano Ziletti, 1556.

Gómez DE LA RegueRA, F. [2011]. Empresas de los Reyes de Castilla con máximas y documentos para príncipes, recogidas, exordenadas e iluminadas por [...] Edición de Nieves Pena Sueiro, A Coruña, SIELAE, 2011.

HorozCO, J. DE [1589]. Emblemas morales, Segovia, Juan de la Cuesta.

JoHnston, H. [2005]. "Catherine of Aragon's pomegranate, revisited" Transactions of the Cambridge Bibliographical Society, Vol. 13, No. 2, 153-173.

LóPEz PozA, S. [2010]. «Emblemática aplicada y artificios de la cultura visual en los juegos caballerescos del Siglo de Oro», en Cultura oral, visual y escrita en la España de los Siglos de Oro, dir. J. Ma ${ }^{\text {. DíEZ }}$ BORque, eds. I. OsunA y E. Llergo, Madrid, Visor, 413-462.
LÓPEz PozA, S. [2011]. “'Nec spe nec metu” y otras empresas o divisas de Felipe II", en Emblemática Trascendente, R. ZAFRA Y J. AzAnza (eds.), Pamplona, Sociedad Española de Emblemática-Universidad de Navarra, 435-456.

López Poza, S. [2012]. «Empresas o divisas de Isabel de Castilla y Fernando de Aragón (los Reyes Católicos)", Janus. Estudios sobre el Siglo de Oro, l (2012), 1-38. <http://www.janusdigital.es/articulo.htm?id=5>. Estudios sobre el Siglo de Oro, 1 (2012), 1-38. <http://www.janusdigital.es/articulo.htm?id=5>.

LoreA, A. DE [1674]. David pecador, enpresas (sic) morales, politico cristianas. Compuesta por el P. presentado F. Antonio de Lorea, Coronista general de la Orden de Predicadores. Dada a la estampa por el Lic. D. Bernardo de Lorea Amescua... En Madrid, por Francisco Sanz, en la Imprenta del Reyno.

MARÍn PINA, M. C. [1990]. "Composición y cronología del Cancionero de Pedro Marcuello", Archivo de Filología Aragonesa, Vol. 44-45, 161-178.

MENÉNDEZ PidAL, F. [2005]. «Tanto monta». El escudo de los Reyes Católicos", en Isabel la Católica vista desde la Academia, Luis Suárez Fernández, coord., Madrid, Real Academia de la Historia, 99-138.

Merino de CÁCEReS, J. M. «El Palacio Real de Segovia, un monumento que desaparece», <http://www.salvarpatrimonio. org/cronicas/palacio-real-segovia.html> 30-07-2013. El artículo fue publicado el 26-7-2005. 
Montalbo, F. A. DE [1689]. Noticias funebres de las magestuosas exequias, que hizo la felicissima Ciudad de Palermo, Cabeça Coronada de Sicilia, en la muerte de Maria Lvysa de Borbon nuestra señora reyna de las Españas. De orden del Excelentissimo señor Dvque de Vzeda, Virrey, y Capitan General deste Reyno. Executada por el Ilvstre D. Luys Riggio Principe de Campo Florido... Que escribia el Maestro Fr. Francisco de Montalbo de la Sagrada Religion de San Geronimo... En Palermo, por Thomas Romolo, Impressor del S. Officio.

NARGANES QuiJANO, F. [2008]. "La emblemática de los Reyes Isabel y Fernando: Ejemplos palentinos", Publicaciones de la Institución Tello Téllez de Meneses, Nº. 79, 7-33.

Osma, G. J. [1909]. Las divisas del rey en los pavimentos de "obra de Manises" del Castillo de Nápoles: (Años 1446-1458). Textos y documentos valencianos: $\mathrm{n}^{\circ}$ III. Apuntes sobre cerámica morisca. Madrid, Fortanet.
PARdo DE Guevara y VAldés, E. [2008]. "Armas de reyes y armas de reinos. La materia heráldica en el Atlas de Pedro Texeira", en Atlas de Pedro Texeira. Descripción de España y de las costas y puertos de sus Reynos (Siglo XVII). Estudios y transcripción, 77-110.

Rolet, A. [2007]. "Aux sources de l'emblème: blasons et devises", Littérature, $\left(\mathrm{n}^{\circ} 145\right)$, 53-78.

SAINZ VARONA, F. A. [1982]. "La moneda de vellón de Enrique IV. La Ordenanza de 1462", en Boletín corporativo de la Academia Burgense, 199, 231-265.

Vega CARPIO, L. F. de [1925]. El castigo del discreto: together with a study of conjugal honor in his theater, by William Leopold Fichter, New York, Instituto de las Españas en los Estados Unidos.

VERARDI, C. [1494]. In laudem Serenissimi Ferdinandi Hispania[rum] regis Bethicx $\theta$ regni Granatae obsidio, victoria, $\theta$ triu $[m]$ phus. Et De insulis in Mari Indico nuper inuentis ([Basel]: I.B. [Johann Bergmann, de Olpe]. 
